\title{
Equitably Linking Integrative Learning and Students' Innovation Capacities
}

\author{
Benjamin S. Selznick ${ }^{1}$ - Laura S. Dahl' • Ethan Youngerman ${ }^{3}$. \\ Matthew J. Mayhew ${ }^{4}$
}

Accepted: 29 June 2021 / Published online: 24 July 2021

(c) The Author(s), under exclusive licence to Springer Nature B.V. 2021

\begin{abstract}
The purpose of this study was to examine the relationship between two recent currents in postsecondary education - integrative learning and undergraduate innovation. We located the rationale for this study in postsecondary educational practices and policies (e.g., inclusive makerspaces, transdisciplinary courses) which have theorized the connection between these two areas yet have not scrutinized this relationship through robust quantitative study. Drawing on a sample of 5,503 undergraduate students attending one of four Universities in the United States, we employed structural equation modeling (SEM) to test the uniqueness of measured constructs as well as examined associations between variables and overall fit in a structural setting. Results indicated the appropriateness of measuring each construct distinctively and provided evidence of a robust relationship between integrative learning and innovation intentions. Additionally, we identified consistent major-specific and identity-based patterns of realizing effects on innovation in association with integrative learning. The study concludes with discussion of findings and implications for educators and academic leaders working to equitably support efforts across these areas.
\end{abstract}

Keywords Integrative learning $\cdot$ Innovation $\cdot$ College students $\cdot$ SEM

During the past decade, postsecondary education has witnessed a substantial shift toward understanding the mechanisms by which students learn to effectively

Benjamin S. Selznick

selznibs@jmu.edu

1 School of Strategic Leadership Studies, James Madison University, 298 Port Republic Road, MSC 1505, Harrisonburg, VA 22807, USA

2 North Dakota State University, Fargo, ND, USA

3 New York University, New York, NY, USA

4 The Ohio State University, Columbus, OH, USA 
integrate sources of knowledge (Barber, 2012, 2020; Youngerman, 2018). Forms of integrative learning - defined as "the demonstrated ability to connect, apply, and/ or synthesize information" (Barber, 2012, p. 593) - have been expressed as crucial to student development not only in terms of academic achievement, but also for their association with success beyond college as students enter the global knowledge economy (Association of American Colleges \& Universities, 2018; Crawford \& Fink, 2020). Simultaneously, students' innovation capacities have also emerged as a highly valued undergraduate outcome among numerous stakeholders (e.g., Selznick \& Mayhew, 2018, 2019). To support innovation - which we define as a process of generating and executing contextually beneficial new ideas (Selznick \& Mayhew, 2018) - Universities have engaged in several large-scale capital projects such as the creation of innovation hubs and makerspaces (Wyllie, 2018). Institutions have also frequently experimented with opportunities for students to engage in enriching academic experiences that seek to spur innovation through involving students in "wicked problems" - issues which have "innumerable causes, are tough to describe, and do not have a right answer" (Cavagnaro \& Fasihuddin, 2016, p. 8; see also McMurtrie, 2019).

Integrative learning and innovation are connected theoretically and practically. Central to theories of integrative learning is the skill of application, in which students transfer learning from one context to a new one (Barber, 2012; Youngerman, 2018); for instance, a student applying the concepts of restorative justice, which they learned in a Sociology course, to events in their residence hall would be an example of integrative learning. This application skill is crucial to innovation as well, as this creative act involves applying a model to a new realm of opportunity (Koestler, 1964; Selznick, 2019; Shane, 2003); a student applying the gig-economy model to develop and implement a new culturally-responsive math curriculum through a community tutoring program, for example, could be an example of innovation.

Despite notable synergies connecting these two learning and developmental streams (e.g., Barber, 2020; McCarthy et al., 2018; Selznick, 2019; Youngerman, 2018), little work to date has sought to empirically demonstrate the relationship between these valued educational phenomena. Initial challenges to such work have been rooted in instrumentation; namely, can the cognitively complex latent constructs of integrative learning and innovation capacities be reliably and validly measured? Subsequent challenges have invited concerns regarding how to examine such relationships as part of college students' learning experiences on the whole rather than with respect to a singular course or experience. In other words, if college itself is the intervention for developing integrative learners and innovators, and the two are connected, how can these phenomena be quantitatively explored with the end goals of promoting inclusive excellence and enhancing educational quality?

In this study, we address challenges associated with both measuring and testing associations with these actionable end goals in mind. Establishing this relationship, we believe, could foster collaborations on campus, helping researchers and practitioners initiate and/or improve integration- and innovation-targeted interventions (e.g., innovation nodes, makerspaces, faculty development centers, learning communities). Additionally, more firmly demonstrating this connection between interdisciplinary ideas and real-world execution might galvanize efforts directed at ensuring 
that all students - not merely some as a function of background characteristics, personality traits, and/or course taking patterns - are able to benefit from integrative and innovation-focused learning experiences. On the reverse, failing to establish this connection beyond a form of what Perna (2016) calls "ordinary knowledge" (p. 327) may have deleterious effects on efforts to incorporate integrative learning practices and innovation capacities, as such endeavors may be left without accurate mechanisms to showcase their distinctive educational benefits and, ultimately, ensure their continued institutional support. Furthermore, the realized and anticipated fiscal hardships imposed by COVID-19 on higher education (e.g., Doyle, 2020), coupled with ever-increasing imperatives on higher education to prove itself accountable for student learning (Kelchen, 2018), accentuate our rationale.

Motivated by a sincere desire to advance and sustain inclusive postsecondary excellence by providing evidence that can support the continued expansion of highquality experiences linking integration and innovation to reach all students, we ask:

1. To what extent does a measurement and structural model testing the relationship between integrative learning practices and innovation intentions fit the data?

2. What is the relationship between integrative learning and innovation intentions with all other model covariates estimated?

3. To what extent is integrative learning associated with major-specific effects on students' innovation intentions?

In a comprehensive effort to respond to these questions, this paper introduces our conceptual and literature foundations, before turning to data sources and structural equation modeling. We close by discussing study significance and potential implications of our work.

\section{Conceptual and Literature Foundations}

To further establish the conceptual relationships between integrative learning and innovation, we briefly introduce each concept. We then consider this relationship in light of students' identities and how such identities have been considered in previous literature.

\section{Integrative Learning}

With respect to integrative learning, Youngerman (2018) draws on new evidence to expand on an initial empirical definition offered by Barber (2012) to discuss not only how students integrate (via connection, application and synthesis) but also what students integrate. While integration may happen between two categorically similar pieces of knowledge (a physics textbook and a drama history textbook), integration may also occur between quite different pieces of knowledge (psychology class and personal experiences as an only child). 
An important strand in the literature on integrative learning also highlights integrations of metacognitive and self-reflective sources (AAC\&U, 2004); integrative learning can occur when students make connections between current learning experiences and previous moments of education. Emphasizing such awareness as its own valuable outcome of education aligns with the emphasis within the innovation literature which highlights the need for students to be aware of opportunities. Turning to how students integrate, empirical research and theoretical writings describe the work that can foster connection, application, and/or synthesis. Key to each of these ways of integrating is bridging - indeed, bridging is itself a category of integration (Youngerman, 2018). By bringing disparate evidence together, students can demonstrate integrative learning via a new idea, a judgment, a real-world application, or by exploring an implication (Barber \& Youngerman, 2021). As this list makes clear, there is often an intellectually creative element to integrative learning.

Developing a measure of integrative learning which takes into consideration both what and how students integrate has been challenging (Barber, 2012). The AAC\&U's (2010) VALUE rubric for integrative learning has proven influential (Rhodes \& Finley, 2013) and has fueled an understanding that integrative learning involves, in particular, students "adapt[ing] and apply[ing] skills, abilities, theories, or methodologies gained in one situation to new situations" (p.2). Drawing on previous efforts, Youngerman et al. (2021) developed a measure of integrative learning with robust psychometric properties, including validity and reliability; the measure highlights student demonstrations of reflecting, applying, contextualizing, and extrapolating (Youngerman et al., 2021).

Both practice and measurement efforts build closely on the concept of transfer of learning - the AAC\&U integrative learning rubric (2010), for example, articulates transfer as one of the five facets of the construct and operationalizes it as, at the highest level, work which "adapts and applies, independently, skills, abilities, theories, or methodologies gained in one situation to new situations to solve difficult problems" (p. 2). The theory of transfer of learning is part of what constitutes this important "transfer" aspect of learning integration. Haskell (2001) further explains that "transfer refers to how previous learning influences current and future learning, and how past or current learning is applied or adapted to similar or novel situations" (p. 23). The literature proposes several typologies of transfer which are useful for understanding integrative learning, which progress from how much adaptation is required to bring existing skills into new settings (i.e., "near" and "far" transfer; see Perkins \& Salomon, 1992) to higher-order forms of relational transfer which involves independently and contextually "seeing the same structure between two things" (Haskell, 2001, p. 32) not obviously in relation. Youngerman et al. (2021) hypothesize that such higher-order and far transfers may be among the more difficult aspects of integrative learning for students. Such a theoretical linkage between transfer of learning, difficult problems, and higher-order cognition is another hinge connecting integrative learning and innovation.

Finally, beyond what and how students integrate, the literature makes clear that such demonstrations do not happen by accident; instead, fostering integrative learning requires intentional framing from faculty and institutions (Barber, 2020). Encouraging students to integrate can be the direct result of prioritizing connection and application 
across the curriculum (e.g., via forms of assessment such as capstone projects; see Finley \& McNair, 2013; Kinzie, 2013), co-curriculum (e.g., via forms of active learning; see Barber, 2014; Youngerman \& Culver, 2019), and outside-of-class connecting experiences (e.g., via community-based projects, Mayhew et al., 2012; Selznick, 2019).

\section{Innovation Intentions}

Moving to innovation, work led by Mayhew, Selznick and colleagues (e.g., Mayhew et al., 2012, 2016; Selznick \& Mayhew, 2018, 2019) has demonstrated that collegiate experiences and environments are associated with the appearance of students' innovation capacities - a set of skills and abilities associated with engaging in the process of generating and executing contextually beneficial new ideas. An essential element of being an innovator, and a sustained topic of inquiry in the scholarship of teaching and learning associated with developing innovators and entrepreneurs, is the emergence of students' intentions to innovate. Operationalized initially by Mayhew et al. (2012) with respect to innovative entrepreneurship and expanded by Selznick and Mayhew (2018) to include non-business applications of innovation (e.g., social, community-based), this concept is based in the work of Shane (2003) and, with respect to measuring intention, Ajzen $(1991,2002)$ and includes four components: opportunity recognition, strategizing, resource acquisition, and creation. The four-item measure of this construct has demonstrated reliability and validity across several studies (e.g., Mayhew et al., 2012, 2016; Selznick \& Mayhew, 2018, 2019).

With an eye toward learning improvement, close consideration has been given throughout this body of work to the pedagogical and experiential avenues that can effectively be implemented to promote and develop undergraduate students' intentions to innovate. One notable area has been the effectiveness of transdisciplinary, problembased settings designed to promote authentic creativity and executing solutions. As Selznick (2019) notes: "[Such] innovation-related efforts - with their introduction of wicked problems and contextual benefit - are perhaps uniquely suited to maximize synergistic partnerships that connect students and faculty across disciplines, campuses to communities, and persistent challenges to new opportunities" (p. 87). In the language of integrative learning, we might consider the importance of inter-/multi-/and trans-disciplinary spaces in promoting innovation through their structured focus on combining knowledge streams to generate novel insights and solutions that could not have possibly emerged from a single discipline (Swayne et al., 2019); we might also consider curricular practices such as double majors as more than simply additive, but instead as opportunities which may foster students integration and innovation (Mayhew \& Selznick, 2018).

\section{Theorizing Relationships between Integrative Learning and Innovation Intentions}

Due to the theoretical proximity between intentions and behaviors (Ajzen, 1991, 2002) and between transdisciplinarity and integration (see Lattuca, 2001), we decided to examine intentions to innovate in their association with integration. In 
this way, we are able to frame discussions of collegiate experiences for their value in promoting those forms of learning integration that may inspire students to innovate.

Numerous efforts have sought to closely examine how such undergraduate experiences can promote these distinctive forms of learning (e.g., synthesis, relational transfer) in association with student outcomes. For example, Hung (2013) addresses how problem-based environments might be especially beneficial to promote forms of learning transfer through learning experiences which incorporate "authentic, contextually meaningful problems" (p. 34); such problems, he suggests, promote selfdirected learning, collaboration, deep questioning, and metacognitive engagement (see Jach and Trolian (2019) for a varied look at problem-based learning and its fostering of transfer). More recently, Barber (2020) names two transfer-infused practices - encouraging juxtaposition and hands-on experiences - which educators can incorporate across educational spaces to promote integrative learning.

Throughout presentations of this work, we also see a close connection between more sophisticated forms of transfer (see Foley \& Kaiser, 2013), holistic learning integration (Barber, 2020), and their applications toward preparing individuals to generate and execute new ideas that can benefit a wide variety of contexts (see also Selznick \& McCarthy, 2020). Building on this cross-disciplinary body of literature we hypothesize, therefore, that a close relationship might exist between students' integrative learning habits of mind and their intentions to enact their synthesis of knowledge, personal growth, and contextual awareness via innovation (e.g., Cavagnaro \& Fasihuddin, 2016).

\section{Testing Across Identities and Majors}

While educators from a theoretical and practical perspective might hope that integrative learning and innovation reach all students, such avenues emerge from and operate within inequitable learning structures (e.g., Perez \& Barber, 2018). We briefly consider this literature along two dimensions: student identities and educational opportunities.

Regarding student identities, Barber (2020) builds on pioneering work led by Baxter Magolda (2004) to suggest that authentic integrative learning must meaningfully draw on students' prior knowledge and comprehensively embrace students' unfolding identities and experiences. As Barber further notes: "We need to acknowledge students' identities and encourage them to bring their whole selves into learning experiences. Educators must open the door for students to bring their identities into a course or experience" (p. 107). Embracing this perspective, we incorporated race/ethnicity and gender identity into our model to better understand the relationship between students' identity patterns and both integrative learning and innovation intentions.

In regards to educational opportunities, we observed throughout the literature (e.g., Mayhew et al., 2012, 2016) a notable effect on major field of study and the appearance of innovation intentions. Specifically, evidence suggests that students pursuing business and/or engineering - through the close associations with entrepreneurship and product development in these curricula - have been advantaged 
in terms of access to educational opportunities designed to foster innovation (see Baumol, 2004; Prince, 2004). Evidence also suggests a distinctive relationship between students pursuing double majors and the appearance of innovation intentions, as well as perhaps more oblique intersections with integrative learning (e.g., Mayhew \& Selznick, 2018). To account for such variability in terms of access to curricula by way of major, our model included several major categories. We now explain our methods.

\section{Methods}

\section{Data Source and Sample}

We used a large, multi-institutional sample to examine the relationship between integrative learning and innovation intentions. The data for this study were drawn from the 2019 administration of the Assessment of Collegiate Residential Environments and Outcomes (ACREO) survey, a project designed to examine the relationship between on-campus environments and student outcomes (ACREO, 2018). Over 36,600 undergraduate students at five public, doctoral universities in the Midwest, Southeast, and Far West were invited to participate in the online survey during the spring of 2019, which yielded an overall response rate of $24.7 \%$. Data were screened for range and listwise deletion was performed to ensure that only complete and original responses were examined. Since one institution did not receive the full integrative learning scale, this study utilized a sample of 5,503 students at four institutions (a usable data rate of $68.9 \%)^{1}$

\section{Variables}

The primary variables for this study consist of a four-item index of students' intention to innovate (Mayhew et al., 2012, 2016; Selznick \& Mayhew, 2018) ${ }^{2}$ and a nineitem index of integrative learning (see Youngerman et al., 2021). The exogenous variable intention to innovate provides one item associated with each of the reduced dimensions of Shane's (2003) model, which moves from opportunity recognition (e.g., "Identifying new opportunities (such as a new product or service, a more effective way of accomplishing tasks, or a new way to solve a common problem)") to creation (e.g., "Creating a new entity to take advantage of new opportunities (for example, a team organization, a business/non-profit, or a club devoted to the new

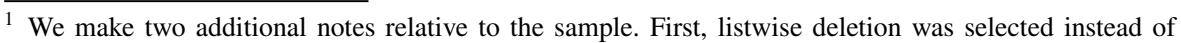
an imputation strategy to ensure that all estimates - especially with respect to student identity patterns - were based on endorsed items. Second, this sample size is sufficiently robust for SEM relative to the number of parameters (Kline, 2015).

2 The original measure presented in Mayhew et al., 2012 considered these four parameters in association with "new business-related opportunities"; this work was extended by Selznick \& Mayhew (2018) and in this study to consider these four parameters in association with "new opportunities".
} 
opportunity)"). The endogenous integrative learning variable synthesizes foundational research (Barber, 2012, 2020; Youngerman, 2018) to provide a unidemsional nine-item factor which includes prompts reflecting connection (e.g., "I often connect a book or article that I am reading for class with a personal experience"), application and transfer (both near and far) (e.g., "When I learn a skill in one course in my major, I often end up using that skill in another course in my major" and "When I learn a skill in my major, I often end up using that skill outside my major"), and synthesis (e.g., "I enjoy extrapolating from concrete observations to abstract ideas"). Both scales have demonstrated high criterion validity, measurement accuracy, and reliability independently of one another. In addition to the latent variables described above, demographic variables were included to control for academic major, gender, race, and institution. See Table 1 for respondent information and Table 2 for full item text and associated measurement information.

\section{Analysis}

Structural equation modeling (SEM) was used to analyze the measurement of these constructs as well as the direct and indirect effects of integrative learning, gender, race, and primary academic major on intention to innovate. Specifically, we adopted a common strategy (Kline, 2015) of first testing our measurement model through use of a confirmatory factor analysis. Given the theoretical associations of our constructs, we were careful to consider model fit relative to a one-dimensional (i.e., all items loading onto a single factor) or two-dimensional (items loading onto their hypothesized constructs) factor structure. Confirming sufficient measurement model fit, we next tested a structural model in which all variables were estimated for their direct effect on intention to innovate, direct effect on integrative learning, and indirect effect on innovation through integration. ${ }^{3}$ All fit statistics were reported and interpreted (see below).

The choice to employ structural equation modeling (SEM) was made for several reasons and with knowledge of its inherent implications and assumptions (see Kline, 2015). First, as these two measures are relatively new and their simultaneous employment in multi-institutional student-level data collection efforts even more contemporary, we sought a strategy that would allow us to demonstrate their quantitative distinctiveness and test possibilities for employment in the same model. Second, we do not offer our model as establishing causal relationships nor suggest that integrative learning causes innovation intentions (see Bollen \& Pearl, 2013). Instead, we tested this model to consider the association between these two latent constructs and their possibility for realization within the higher education context, as well as to consider their possible connections in the presence of student identities. Finally, we use this model as it is authentic to how educators and administrators in these spaces themselves speak about these phenomenon - that promoting integration

\footnotetext{
3 The four-institution model was selected after two separate models - which estimated, as a function of sample distribution, Far West alone and Great Lakes 1, 2, and Southeast alone - demonstrated similar model fit statistics and parameter estimates.
} 
Table 1 Respondent Demographic Information $(N=5,503)$

\begin{tabular}{lll}
\hline & $N$ & $\%$ \\
\hline Planned Academic Major & & \\
Science, Technology, or Mathematics & 1,610 & $29.3 \%$ \\
Social Sciences or Education & 1,206 & $21.9 \%$ \\
Arts and Humanities & 538 & $9.8 \%$ \\
Engineering & 531 & $9.7 \%$ \\
Health Professions & 519 & $9.4 \%$ \\
Double Major & 490 & $8.9 \%$ \\
No Major Selected & 325 & $5.9 \%$ \\
Business Administration & 284 & $5.2 \%$ \\
Race/Ethnicity & & \\
White & 2,179 & $39.6 \%$ \\
Asian/Asian American/Pacific Islander & 1,714 & $31.1 \%$ \\
Hispanic or Latina/o/x & 628 & $11.4 \%$ \\
More than one race/ethnicity & 553 & $10.0 \%$ \\
Native American or another race/ethnicity & 221 & $4.0 \%$ \\
Black or African American & 208 & $3.8 \%$ \\
Gender & & \\
Cisgender Woman & 3,630 & $66.0 \%$ \\
Cisgender Man & 1,722 & $31.3 \%$ \\
Trans* and Nonbinary & 151 & $2.7 \%$ \\
University & & \\
Far West & 3,841 & $69.8 \%$ \\
Great Lakes 1 & 868 & $15.8 \%$ \\
Southeast & 686 & $12.5 \%$ \\
Great Lakes 2 & 108 & $2.0 \%$ \\
\hline
\end{tabular}

is inexorably intertwined with innovation intentions (Heinrich et al., 2021), often especially for those (e.g., not White males studying business and engineering) who have been historically excluded from innovation-related narratives (e.g., Mayhew et al., 2012; Selznick, 2019).

\section{Limitations}

This study is not without its limitations. To begin, we considered the important epistemological limitation that truly understanding the complexities of college student learning and its potential associations can demand multi-paradigmatic forms of inquiry beyond the scope of this study or its data (Lattuca et al., 2014). Additionally, SEM and its associated directionality perhaps artificially imposed a structure that may ultimately be inauthentic to how students experience learning, educators experience teaching, and college experiences holistically unfold. In order to draw what we believe are important and rigorous statistical inferences, we measured and modeled variables associated with student learning through these techniques. Yet, we do 


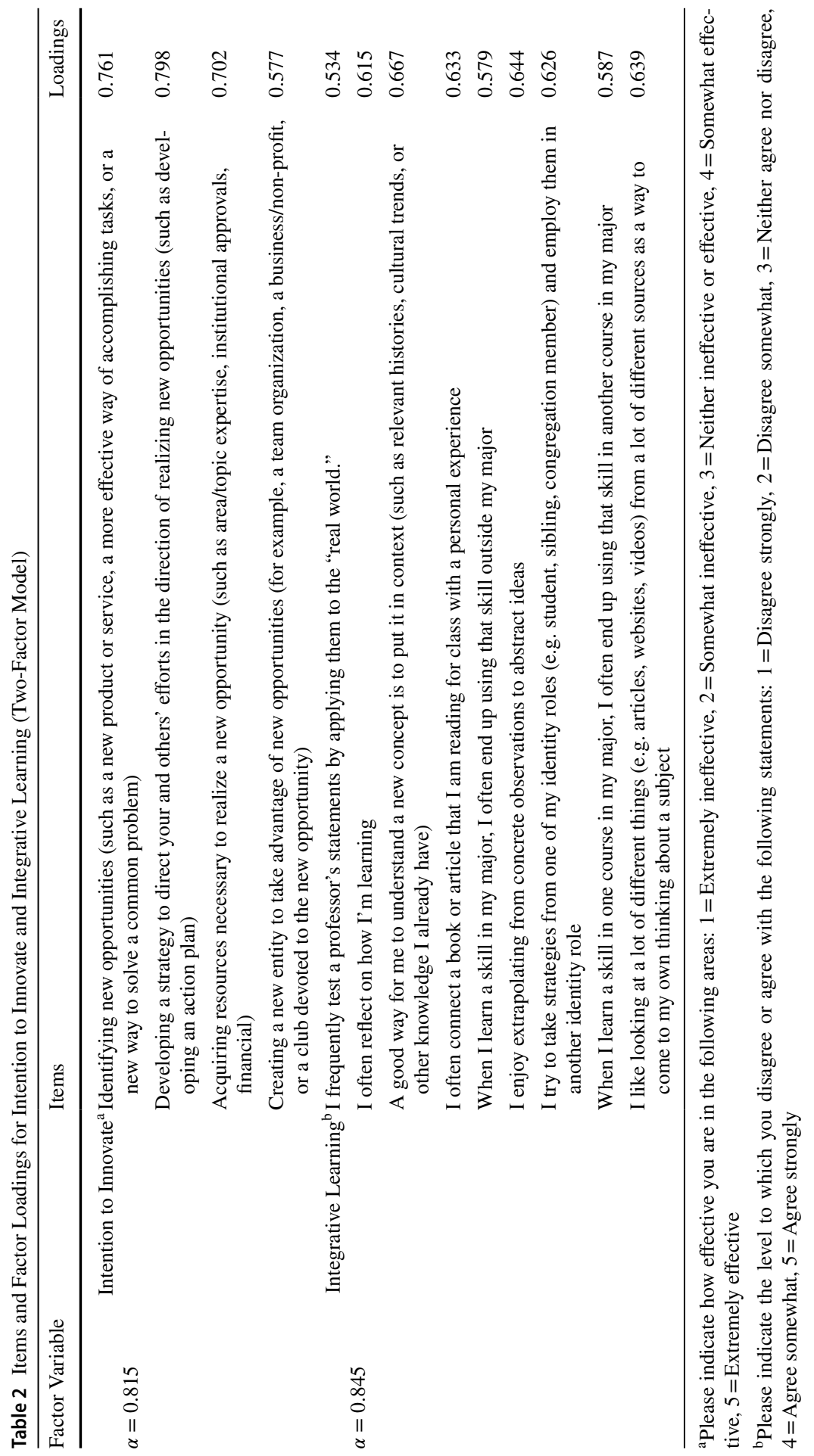


understand that such approaches may not comprehensively capture the full scope of learning (see Lattuca et al., 2014).

We also considered that while our student sample is statistically powered relative to our analysis, our institutional sample and its subsequent representation are not fully indicative of the expansive presentation of higher learning institutions and their populations in the United States. To empirically, if modestly, account for institutional-level features we included dummy-coded institutional variables in our model, although we left any results uninterpreted given their lack of measurement specificity. Additionally, we understand the inherent challenges in using broad-based identification categories (e.g., Female, Latinx) which cannot fully account for heterogeneous student presentations, intersectionality and its associated (dis)empowerments, or all possible categories due to model assumptions. We saw these as unfortunate yet necessary tradeoffs, and urge that though our findings emerged through use of a structural equation modeling approach, they be interpreted as associations existing within their data context, not as causal inferences nor as findings generalizable to all postsecondary settings and participants (Wolniak et al., 2020).

\section{Results}

\section{RQ1: Testing the Measurement and Structural Models}

Prior to testing the structural model, we estimated two models using confirmatory factor analysis to further examine our instrumentation: a one factor model with all innovation and integrative learning items and a two-factor model which separated items into their home scales. Traditional indices of fit were considered, including CFI $\geq 0.90$ and TLI $\geq 0.90$ for good fit (Hoyle, 1995) and RMSEA $\leq 0.05$ for excellent fit (Kline, 2015). Chi-square estimates were also examined, noting that this statistic is particularly sensitive to large samples (Brown, 2015). The initial measurement model, which included all 13 items related to integrative learning and intention to innovate as one factor, demonstrated fit indices of $\chi^{2}(65)=5150.961, p<0.001$; $\mathrm{CFI}=0.777 ; \mathrm{TLI}=0.732 ; \mathrm{RMSEA}=0.122 \quad(90 \%$ confidence interval $=[0.119$, $0.125]$ ); $\mathrm{SRMR}=0.082$, which is indicative of a weak fit. The second model, which treated the two constructs as separate factors, demonstrated more robustness than a one factor model: $\chi^{2}(62)=966.611, p<0.001 ; \mathrm{CFI}=0.962 ; \mathrm{RMSEA}=0.051(90 \%$ $\mathrm{CI}=[0.049,0.054]) ; \mathrm{SRMR}=0.031$. These findings indicate that the items, as intended, measure two distinctive constructs.

We then estimated an integrated measurement and structural model to examine the direct paths between all exogenous variables, integration and innovation and indirect paths of each exogenous variable through the integrative learning factor. The combined measurement and structural model added academic major (business administration as reference), gender (cisgender men as reference), race (white as reference), and institution (Far West as reference) as exogenous variables. Overall, the structural model demonstrated robust fit indices: $\mathrm{CFI}=0.932$; $\mathrm{TLI}=0.919 ; \quad \mathrm{RMSEA}=0.035 \quad(90 \% \quad \mathrm{CI}=[0.034,0.036]) ; \quad \mathrm{SRMR}=0.022 ;$ $\chi^{2}(249)=1925.822, p<0.001$. Figure 1 depicts the final model, with those paths 


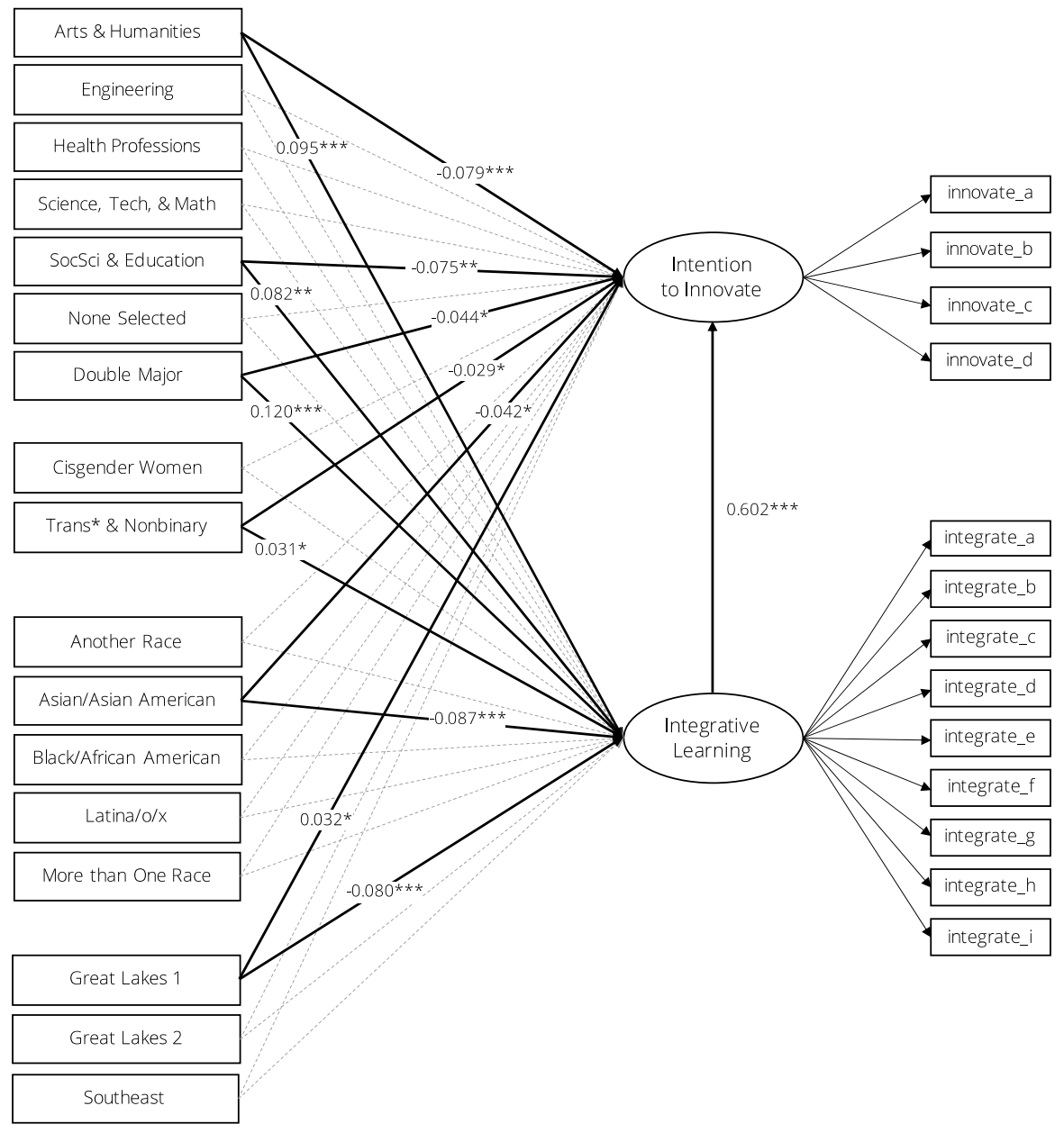

Fig. 1 Final structural model with main and indirect effects

not found to be significant as both main and indirect effects noted as dotted lines. The standardized coefficients estimated for all the variables in the final model are presented in Table 3 .

\section{RQ2 and 3: Effects of Integrative Learning and Academic Major on Innovation Intentions}

The analysis revealed integrative learning had a significant positive association with intention to innovate $(\beta=0.602, p<0.001)$. Furthermore, when compared to the reference group (business administration), majoring in arts and humanities $(\beta=-0.079$, $p<0.001)$; science, technology, or math $(\beta=-0.073, p=0.011)$; and social science and education $(\beta=-0.075, p=0.004)$ holds a direct negative relationship with 
Table 3 Structural Model Estimates

\begin{tabular}{|c|c|c|c|}
\hline Parameter Estimate & $\beta$ & SE & Sig \\
\hline \multicolumn{4}{|l|}{ Intention to Innovate $\leftarrow$} \\
\hline Integrative Learning & 0.602 & 0.012 & $* * *$ \\
\hline Arts and Humanities & -0.079 & 0.021 & $* * *$ \\
\hline Engineering & 0.012 & 0.021 & \\
\hline Health Professions & -0.037 & 0.021 & \\
\hline Science, Technology, or Math & -0.073 & 0.029 & $*$ \\
\hline Social Science and Education & -0.075 & 0.026 & $* *$ \\
\hline No Major Selected & -0.051 & 0.019 & $* *$ \\
\hline Double Major & -0.044 & 0.021 & $*$ \\
\hline Cisgender Women & 0.039 & 0.014 & $* *$ \\
\hline Trans* and Nonbinary & -0.029 & 0.014 & $*$ \\
\hline Asian/Asian American/Pacific Islander & -0.422 & 0.017 & $*$ \\
\hline Black or African American & -0.027 & 0.013 & $*$ \\
\hline Hispanic or Latina/o/x & -0.045 & 0.015 & $* *$ \\
\hline More than one race/ethnicity & 0.011 & 0.015 & \\
\hline Native American or another race/ethnicity & 0.003 & 0.014 & \\
\hline Great Lakes 1 & 0.032 & 0.016 & $*$ \\
\hline Great Lakes 2 & 0.032 & 0.013 & $*$ \\
\hline Southeast & 0.030 & 0.015 & $*$ \\
\hline \multicolumn{4}{|l|}{ Integrative Learning $\leftarrow$} \\
\hline Arts and Humanities & 0.095 & 0.023 & $* * *$ \\
\hline Engineering & -0.033 & 0.024 & \\
\hline Health Professions & 0.003 & 0.023 & \\
\hline Science, Technology, or Math & -0.037 & 0.032 & \\
\hline Social Science and Education & 0.082 & 0.029 & $* *$ \\
\hline No Major Selected & -0.002 & 0.021 & \\
\hline Double Major & 0.120 & 0.023 & $* * *$ \\
\hline Cisgender Women & -0.006 & 0.015 & \\
\hline Trans* and Nonbinary & 0.031 & 0.015 & $*$ \\
\hline Asian/Asian American/Pacific Islander & -0.087 & 0.019 & $* * *$ \\
\hline Black or African American & -0.002 & 0.015 & \\
\hline Hispanic or Latina/o/x & 0.002 & 0.017 & \\
\hline More than one race/ethnicity & -0.010 & 0.016 & \\
\hline Native American or another race/ethnicity & -0.011 & 0.015 & \\
\hline Great Lakes 1 & -0.080 & 0.017 & $* * *$ \\
\hline Great Lakes 2 & 0.003 & 0.015 & \\
\hline Southeast & -0.023 & 0.017 & \\
\hline
\end{tabular}

innovation capacities. Not having declared a major $(\beta=-0.051, p=0.007)$ or declaring a double major $(\beta=-0.044, p=0.034)$ demonstrated similar associations with innovation when compared to business administration majors. 
Integrative learning played a partial mediating role from the exogenous variables to intention to innovate. A positive indirect effect through integrative learning was detected for arts and humanities $(\beta=0.095, p<0.001)$ and social science and education majors $(\beta=0.082, p=0.005)$, as well as those with double majors $(\beta=0.120$, $p<0.001)$.

\section{Effects by Gender and Race}

Results also revealed a relationship between gender and innovation intention, with direct positive associations noted for cisgender women $(\beta=0.039, p=0.005)$ and direct negative associations noted for trans* and nonbinary students $(\beta=-0.029$, $p=0.031$ ) when compared to cisgender men. Negative direct relationships with respect to intention to innovate were also noted for Asian/Asian American/Pacific Islander $(\beta=-0.042, p=0.015)$, Black or African American $(\beta=-0.027, p=0.045)$, and Hispanic or Latina/o/x students $(\beta=-0.045, p=0.003)$ when compared to white students. Integrative learning, however, played a partial mediating role to innovation for trans* and nonbinary students $(\beta=0.031, p=0.036)$ while holding a similar negative relationship among Asian/Asian American/Pacific Islander students $(\beta=-0.087, p<0.001)$.

\section{Discussion and Implications}

Integrative learning and innovation intentions are distinct, yet strongly related, outcomes important to the study of higher education. The efficacy of our measurement model demonstrates the reliability, validity and distinctiveness of our two primary scales. Given the close connection between these emergent domains of inquiry, providing empirical evidence of a two-factor model works to the benefit of both integration- and innovation-targeted interventions by creating opportunities for what we believe can and should be an authentic two-way dialogue between these areas and their champions.

Relatedly, the multitude of stakeholders present within the innovation space (e.g., McMurtrie, 2019; Wyllie, 2018) have increasingly sought to tie the emergence of innovation-specific experiences to an expansive presentation of learning practices. Such imperatives go well beyond any association between innovation and entrepreneurship, instead seeking practices and channels within the wider undergraduate curriculum for what works to support innovators across disciplines (see Swayne et al., 2019). On this front, establishing innovation intentions as distinctive from yet still related to integrative learning provides a clear empirical picture of a more nuanced and comprehensive learning paradigm than has been previously studied.

At the item level, we observe two intriguing themes that hold potential to tighten connections between theory, measurement, and practice as a unified whole: context and strategic application. Both scales incorporate the importance of understanding and applying new knowledge relative to the context(s) in which any learning and its subsequent application occurs by the student (Barber, 2020; 
Baxter Magolda, 2004). For integration and innovation to occur, context is not background noise; it is foreground signal. Building on this foundation, the constructs both carefully consider synthesis across contexts (integrative learning) and application of beneficial new ideas into contexts (innovation). While such an insight may well seem obviated to contemporary learning theorists, reliably and validly centering context quantitatively in the space of college student learning is an idea that has gained traction only recently within the past decade and which we hope this research furthers (see Stage, 2007).

To the second theme, both integrative learning and innovation as measured here seek to support the learner didactically in going 'beyond the spark' through including considerations for strategic application. If, paraphrasing the aphorism, realized genius is far more a function of perspiration than inspiration, then equipping students with the cognitive abilities to consider how to strategically build on their insights and progress beyond the inspiration stage should be a focal point of higher learning (see also Barber, 2020). Our distinctive measures, we believe, demonstrate comprehensive and measurable avenues toward realizing these ambitious, yet necessary, goals.

Moving on to the full structural model, we find a similar and intriguing pattern present across three major categories (arts \& humanities, social sciences \& education, double major) and one identity dimensions (trans* \& nonbinary): a negative direct effect on intention to innovate and a positive direct effect on integrative learning. Such findings merit additional discussion, especially when set against our theoretical and practical considerations.

With respect to major, and noting that all categories were estimated against Business Administration majors, we ask: What accounts for these patterns? We offer a number of possible reasons. First, given the curricular evolution of innovation into the domains of business - and, more recently, engineering - we are unsurprised to see a negative association between these areas with respect to innovation intentions when these relationships are considered on their own terms. Do most institutions organizationally consider those students outside of business and engineering departments as innovators and, potentially, future entrepreneurs? In rhetoric perhaps, but not always in practice. Hence, when innovation-specific curricula, knowledge bases, and associated pedagogies are located - either in the formal curriculum, or in the curriculum as perceived by students - behind layers of required business courses, engineering labs, and/or within difficult to access entrepreneurship centers, such learning may be inaccessible to those outside these disciplines.

Integrative learning, at least according to our model, holds the potential to fundamentally shift the innovation equation. We speculate that the positive pathways to innovation through integrative learning for arts, humanities, social science, and/or education majors quantitatively demonstrate and support a theoretical speculation: when integration works in the direction of contextual innovation, all students can benefit. In this sense, we speculate that when students in these majors are provided opportunities to connect, apply, and synthesize, they could also come to realize that they hold the unique power to translate their newfound skills and abilities into meaningful practice (Swayne et al., 2019). 
Results also suggest that students who identify as trans* \& non-binary follow a similar pattern: negatively associated with intention to innovate yet positively associated with integrative learning and, through that path, innovation. While interpreting the fullness of this finding admittedly falls beyond our immediate expertise, and while we understand that this category may include multiple representations of gender, we considered leading work by Nicolazzo (2017) to help us interpret this insight. Nicolazzo (2017) proposes a trans* epistemology as a grounding for liberation, observing with respect to the trans* community that "it is by each other's sides that we can commune and create a world in which possibilities for our gendered pasts/presents/futures are proliferated rather than stifled" (p. 12). Drawing on this epistemic perspective, we offer that our finding could be reflecting how trans* students, historically and presently minoritized by educational and social institutions, may be acutely aware of how their personal experiences exist within structurally oppressive systems and thus exercise integrative learning (e.g., connecting the concrete to the abstract or applying theory to lived experience) toward creating and executing original, inclusive ideas.

Finally, we see negative direct relationships between both integrative learning and intention to innovate among students identifying as Asian/Asian American. We recognize that such a category is insufficient to draw any larger-scale inferences, especially provided the heterogeneity within this quantitative category (Poon et al., 2015). To provide a baseline of insight, though, we wonder whether perhaps such students in our sample may have felt, as a function of campus climates, educator intentions, or sociocultural factors beyond the scope of our study, less invited than others to bring their whole selves and their multitude of personal and cultural experiences into their postsecondary learning (see also Perez \& Barber, 2018).

\section{Implications}

Connecting findings to practice, institutions may wish to consider curricular interventions which promote integration and innovation. A fruitful locus for such encouragement may be First-Year Composition, perhaps the most commonly taken course across higher education in the United States (Brint et al., 2009). Barber and Youngerman (2021) have outlined practical strategies for fostering integrative learning in such courses, including reflective prompts and strategies for incorporating students' emotions into their writing. Prompts and assignments which encourage integration and innovation could be seamlessly incorporated into writing classrooms across the country. Instructors could ask students to articulate a genuine problem in their own college experience and then suggest several innovative responses to that problem, transferring learning from students' other courses and their own knowledge of the campus. Or students could be asked to write an op-ed in which they argue for the application of a previously proven strategy in a new setting.

In a similar vein, we speculate that capstone projects and other culminating experiences, which are typically designed to both incorporate and assess integrative learning, could more intentionally engage with innovation by calling for students to propose a new solution to or application for the project. Provided the nature of these 
linkages, academic policymakers and other stakeholders might consider how such experiences could meaningfully occur and be assessed in student teams, advised by both faculty and community stakeholders. This shift could potentially open the doors to a form of full participation unbound by discipline and which directly includes valuable funds of community knowledge (e.g., Selznick \& McCarthy, 2020).

We also encourage that innovation centers and makerspaces might now be framed as integration centers and application spaces. This is not merely a rebranding; concretizing the association between intention to innovate and integrative learning can help efforts to inject innovation more forcefully into the academic bloodstream. Furthermore, closer attention to the programming and use of these spaces may further extend our finding that innovation is for arts, humanities, social science, and education majors, as well as those identifying as another gender identity as much as it is for anyone else on campus.

Across all practice implications, we urge educators working at the intersections of integrative learning and innovation to be mindful of their roles in creating welcoming climates for students to bring their full selves into their learning, inclusive not only of prior knowledge bases and experiences but also each students' unique potential to recognize and act on previously unrealized opportunities. For students to truly engage in forms of synthesis that generate impact, rather than simply attempt to address what are perceived as 'common problems', all sources of experiences, social networks, culture, and identities must be valued and cultivated. Incorporating the perspectives of Barber (2020) and Swayne et al. (2019), we speculate that one approach to achieving this reality in practice is to decouple innovation from entrepreneurship (thereby expanding access) while recoupling learning and the learner (Baxter Magolda, 2004), thereby centering prior knowledge and ongoing development. This approach, when institutionally supported, may well have the effect of overcoming previous limitations and ensuring enhanced equity in these spaces.

Intriguingly with respect to conceptual implications, we note here that higher education outcomes often exist together. Despite necessary efforts to deconstruct outcomes - mostly due to the need for assessment efficiencies (see Astin, 1993) - higher education scholars must concede that the different forms of learning colleges hope to promote often occur simultaneously, albeit at different rates. For example, how could we expect students to develop meaningful critical thinking skills without a modicum of learning about diverse perspectives? To develop a civic sensibility without understanding self-in-relation to other and moral reasoning? If we are truly to take up the charge of educating the whole student, then future studies like ours which comprehensively measure new outcomes and rigorously relate them to each other are needed.

Thinking across these implications, we build on the work of Barber (2020) and others (e.g., Selznick \& McCarthy, 2020) to remind that the relationship between integration and innovation can be - indeed must be - reinforced and engaged across all fields of study and identity patterns. We speculate that as postsecondary institutions progress through the 2020s, they will need to further and more demonstratively articulate both their value and their values to stakeholders (including prospective students, parents, institutional leaders, donors, and lawmakers). To that end, we hope that the perspectives engaged in this study might serve as a contributor 
to reimagined postsecondary platforms (Heinrich et al., 2021) which recognize that holistic student learning holds potentially greater promise than narrowly-focused job training; that learning partnerships with inspirational faculty can catalyze new ideas in ways that short-term credentialling cannot (Baxter Magolda, 2004); and that both private and, crucially, public returns to postsecondary education rely on ensuring that students are able to transform insight into impact.

\section{Conclusion}

Given the current postsecondary landscape, an expansion toward equitable participation with respect to innovation and integrative learning deserves close attention. In the face of prevailing ecological, public health, and anti-democratic headwinds, higher education holds the possibility to offer signature experiences through which new insights and connections actively support open-ended discovery and motivate life-long applications. This is the college education the twenty-first century demands, and one we hope to inspire.

\section{References}

Ajzen, I. (1991). The theory of planned behavior. Organizational Behavior and Human Decision Processes, 50, 179-211. https://doi.org/10.1016/0749-5978(91)90020-T

Ajzen, I. (2002). Perceived behavioral control, self-efficacy, locus of control, and the theory of planned behavior. Journal of Applied Social Psychology, 32, 1-20. https://doi.org/10.1111/j.1559-1816. 2002.tb00236.x

Assessment of Collegiate Residential Environments and Outcomes. (2018). Annual Report. https://stati c1.squarespace.com/static/588b8364579fb3ba0282970e/t/5bbb7073e5e5f0f20c6dedc2/1539010677 702/2018+ACREO+Report.pdf.

Association of American Colleges \& Universities. (2004). A statement on integrative learning. http:// www.evergreen.edu/washingtoncenter/docs/intlearning/statementintlearning.pdf

Association of American Colleges \& Universities. (2010) Integrative learning VALUE rubric. http:// www.aacu.org/value/rubrics/pdf/integrativelearning.pdf.

Association of American Colleges and Universities. (2018). Fulfilling the American dream: Liberal education and the future of work. Hart Research Associates.

Astin, A. W. (1993). What matters in college: Four critical years revisited. Jossey-Bass.

Barber, J. P. (2012). Integration of learning: A grounded theory analysis of college students' learning. American Educational Research Journal, 49(3), 590-617. https://doi.org/10.3102/0002831212 437854

Barber, J. P. (2014). Integration of learning model: How college students integrate learning. New Directions for Higher Education, 165, 7-17. https://doi.org/10.1002/he.20079

Barber, J. P. (2020). Facilitating the integration of learning: Five research-based practices to help college students connect learning across disciplines and lived experience. Stylus.

Barber, J. P., \& Youngerman, E. (2021). Integrative learning as a process for linking writing and emotion. In C. Wynn (Ed.), Emotions and writing. Peter Lang.

Baumol, W. J. (2004). Education for innovation: Entrepreneurial breakthroughs vs. corporate incremental improvements. Working Paper 10578, NBER.

Baxter Magolda, M. (2004). Learning partnerships model. In M. Baxter Magolda \& P. M. King (Eds.), Learning partnerships: Theory and models of practice to educate for self-authorship (pp. 37-62). Stylus. 
Bollen, K. A., \& Pearl, J. (2013). Eight myths about causality and structural equation models. In S. Morgan (Ed.), Handbook of causal analysis for social research (pp. 301-328). Springer. https://doi.org/ 10.1007/978-94-007-6094-3_15

Brint, S., Proctor, K., Murphy, S. P., Turk-Bicakci, L., \& Hanneman, R. A. (2009). General education models: Continuity and change in the U.S. Undergraduate Curriculum, 1975-2000. The Journal of Higher Education, 80(6), 605-642. https://doi.org/10.1080/00221546.2009.11779037

Brown, T. A. (2015). Confirmatory factor analysis for applied research (2nd ed.). Guilford.

Cavagnaro, L. B., \& Fasihuddin, H. A. (2016). A moonshot approach to change in higher education: Creativity, innovation, and the redesign of academia. Liberal Education, 102, 8-17.

Crawford, P., \& Fink, W. (2020). From academia to the workforce: Critical growth areas for students today. Association of Public \& Land Grant Universities. https://www.aplu.org/library/from-acade mia-to-the-workforce-critical-growth-areas-for-students-today/file.

Doyle, W. R. (2020). Throwing out the "recession playbook" for higher education: The need for joint federal-state policy in the wake of COVID-19. Third Way. https:/www.thirdway.org/ report/throwing-out-the-recession-playbook-for-higher-education-the-need-for-joint-feder al-state-policy-in-the-wake-of-covid-19.

Finley, A., \& McNair, T. (2013). Assessing underserved students' engagement in high-impact practices. AAC\&U.

Foley, J. M., \& Kaiser, L. M. R. (2013). Learning transfer and its intentionality in adult and continuing education. New Directions for Adult and Continuing Education, 137, 5-15. https://doi.org/10.1002/ ace. 20040

Haskell. (2001). Transfer of learning: Cognition and instruction. Academic.

Heinrich, B., Ludwig, P., Lewis, E., McCarthy, S., Swayne, N., \& Louson, E. (2021). Testing assessments of integrated learning. In A. Peck \& D. M. DeSawal (Eds.), Applying design thinking to the measurement of experiential learning. IGI Global.

Hoyle, R. H. (Ed.). (1995). Structural equation modeling: Concepts, issues, and application. SAGE.

Hung, W. (2013). Problem-based learning: A learning environment for enhancing learning transfer. New Directions for Adult and Continuing Education, 137, 27-38. https://doi.org/10.1002/ace.20042

Jach, E. A., \& Trolian, T. L. (2019). Defining applied learning and related student outcomes in higher education. In J. L. Kinzie (Ed.), Applied learning in higher education: Curricular and co-curricular experiences that improve student learning (New Directions for Higher Education, No. 188). Jossey-Bass.

Kelchen, R. (2018). Higher education accountability. Johns Hopkins University Press.

Kinzie, J. (2013). Taking stock of capstones and integrative learning. Peer Review, 15(4), 27-30.

Kline, R. B. (2015). Principles and practice of structural equation modeling (4th ed.). Guilford.

Koestler, A. (1964). The act of creation. Macmillan.

Lattuca, L. (2001). Creating interdisciplinarity: Interdisciplinary research and teaching among college and university faculty. Vanderbilt University Press.

Lattuca, L., Cox, R., Mesa, V., \& Reason, R. (2014). Studying learning in higher education: A conversation about current approaches and future directions. Symposium presented at the annual meeting of the Association for the Study of Higher Education (ASHE), Washington, DC.

Mayhew, M. J., \& Selznick, B. S. (2018). Why double-majors might beat you out of a job. The Conversation. https://theconversation.com/why-double-majors-might-beat-you-out-of-a-job-92798.

Mayhew, M. J., Simonoff, J. S., Baumol, W. J., Wiesenfeld, B. M., \& Klein, M. W. (2012). Exploring innovative entrepreneurship and its ties to higher educational experiences. Research in Higher Education, 53, 831-859. https://doi.org/10.1007/s11162-012-9258-3

Mayhew, M. J., Simonoff, J. S., Baumol, W. J., Selznick, B., \& Vassallo, S. (2016). Cultivating innovative entrepreneurs for the 21st century: A study of U.S. and German students. The Journal of Higher Education, 87(3), 420-455. https://doi.org/10.1080/00221546.2016.11777408

McCarthy, S., Barnes, A., Holland, S. K., Lewis, E., Ludwig, P., \& Swayne, N. (2018). Making it: Institutionalizing collaborative innovation in public higher education. $4^{\text {th }}$ International Conference on Higher Education Advances (HEAd'18). http://www.headconf.org/head18-papers-published/.

McMurtrie, B. (2019). No textbooks, no lectures, and no right answers. Is this what higher education needs? The Chronicle of Higher Education. https://www.chronicle.com/article/No-Textbooks-NoLectures-and/245640.

Nicolazzo, Z. (2017). Imagining a trans* epistemology: What liberation thinks like in postsecondary education. Urban Education. https://doi.org/10.1177/0042085917697203 
Perez, R. J., \& Barber, J. P. (2018). Intersecting outcomes: Promoting intercultural effectiveness and integration of learning for college students. Journal of Diversity in Higher Education, 11(4), 418-435. https://doi.org/10.1037/dhe0000067

Perkins, D. N., \& Salomon, G. (1992). The science and art of transfer. In A. L. Costa, J. A. Bellanca, \& R. Fogarty (Eds.), If minds matter: A forward to the future (Vol. 1, pp. 201-209). Skylight Publishing.

Perna, L. (2016). Throwing down the gauntlet: Ten ways to ensure that higher education research continues to matter. The Review of Higher Education, 39(3), 319-338. https://doi.org/10.1353/rhe.2016. 0016

Prince, M. (2004). Does active learning work? A review of the research. Journal of Engineering Education, 93(3), 1-9. https://doi.org/10.1002/j.2168-9830.2004.tb00809.x

Poon, O., Squire, D., Kodama, C., Byrd, A., Chan, J., Manzano, L., Furr, S., \& Bishundat, D. (2015). A critical review of the model minority myth in selected literature on Asian Americans and Pacific Islanders in higher education. Review of Educational Research, 20(10), 1-34. https://doi.org/10. $3102 / 0034654315612205$

Rhodes, T., \& Finley, A. (2013). Using the VALUE rubrics for improvement of learning and authentic assessment. AAC\&U. https://www.eou.edu/ctl/files/2012/10/E-VALRUBR2.pdf.

Selznick, B. S. (2019). Developing innovators: Preparing $21^{\text {st }}$ century graduates for the idea economy. In T. Trolian \& E. Jach (Eds.), New directions for higher education, 181 (pp. 81-90). Wiley.

Selznick, B. S., \& Mayhew, M. J. (2018). Measuring undergraduates' innovation capacities. Research in Higher Education, 59(6), 744-764. https://doi.org/10.1007/s11162-017-9486-7

Selznick, B. S., \& Mayhew, M. J. (2019). Developing first-year students' innovation capacities. Review of Higher Education, 42(4), 1607-1634. https://doi.org/10.1353/rhe.2019.0077

Selznick, B., \& McCarthy, S. (2020). Toward a theory of social innovation for higher education. In A. J. Fulford (Ed.) Philosophy and Theory in Higher Education (Vol. 2, Issue 3, pp. 49-69). Peter Lang.

Shane, S. A. (2003). A general theory of entrepreneurship: The individual-opportunity nexus. Edward Elgar.

Stage, F. K. (2007). Answering critical questions using quantitative data. New Directions for Institutional Research, 131, 5-16.

Swayne, N., Selznick, B. S., McCarthy, S., \& Fisher, K. A. (2019). Uncoupling innovation and entrepreneurship to improve undergraduate learning. Journal of Small Business and Enterprise Development, 26(6/7), 783-796. https://doi.org/10.1108/jsbed-04-2019-0122

Wolniak, G., Chang, M. J., Doyle, W., \& Flores, S. M. (2020). Inclusivity? Causality? Reasonable compromises in quantitative research. Interactive symposium presented at the annual meeting of the Association for the Study of Higher Education (ASHE), New Orleans, LA [Remote].

Wyllie, J. (2018). Colleges have spent big money on innovation centers. Do they work? The Chronicle of Higher Education. https://www.chronicle.com/article/Colleges-Have-Spent-Big-Money/242992.

Youngerman, E. (2018). Integrative learning in award-winning student writing: A grounded theory analysis. AERA Open, 4(3), 1-13. https://doi.org/10.1177/2332858418788825

Youngerman, E., Dahl, L. S., \& Mayhew, M. J. (2021). Examining the psychometric properties of a new integrative learning scale. Research in Higher Education. https://doi.org/10.1007/ s11162-021-09623-1

Youngerman, E., \& Culver, K. C. (2019). Problem-based learning (pbl): Real-world applications to foster (inter)disciplinary learning and integration. In T. Trolian \& E. Jach (Eds.), New Directions for Higher Education, 181 (pp. 23-32). Wiley.

Publisher's Note Springer Nature remains neutral with regard to jurisdictional claims in published maps and institutional affiliations. 
Benjamin S. Selznick is an assistant professor of strategic leadership in the School of Strategic Leadership Studies at James Madison University.

Laura S. Dahl is an assistant professor of education at North Dakota State University.

Ethan Youngerman is a senior language lecturer in the Expository Writing Program at New York University.

Matthew J. Mayhew is the William Ray and Marie Adamson Flesher Professor of Educational Administration with a focus on Higher Education and Student Affairs at The Ohio State University. 